\title{
Behavior of ultrafine particles in continental and marine air masses at a rural site in the United Kingdom
}

\author{
Hugh Coe and Paul I. Williams \\ Physics Department, University of Manchester Institute of Science and Technology, Manchester, England, U.K.
}

\author{
Gordon McFiggans ${ }^{1}$ \\ School of Environmental Sciences, University of East Anglia, Norwich, England, U.K.
}

\author{
Martin W. Gallagher, Karl M. Beswick, Keith N. Bower, and Tom W. Choularton \\ Physics Department, University of Manchester Institute of Science and Technology, Manchester, England, U.K.
}

\begin{abstract}
Particle size distribution measurements were made at a coastal site in the United Kingdom. These are presented, and the behavior of recently formed ultrafine particles is discussed. No ultrafine particles were observed in maritime air masses; however, 3 to $7 \mathrm{~nm}$ particles were frequently observed at enhanced concentrations when the wind direction was from the land. Their formation was favored at lower temperatures, when 1 ppbv or more of $\mathrm{SO}_{2}$ was present and in air masses that had not been aged extensively. On days when enhanced ultrafine particle concentrations were observed, $3 \mathrm{~nm}$ particles increased sharply in the morning, approximately 30 to $90 \mathrm{~min}$ after the UV solar flux first increased. By early afternoon the ultrafine particle concentration had returned to background levels. Rapid measurements of $5 \mathrm{~nm}$ particles showed no correlation with turbulence parameters, although the boundary layer mixing scales were similar to growth times of freshly nucleated particles to 5 $\mathrm{nm}$ diameter. However, ultrafine particle concentrations do correlate with the availability of sulphuric acid vapor. A delay of approximately an hour between the increase of $\mathrm{H}_{2} \mathrm{SO}_{4}$ in the morning and a large increase in ultrafine particle concentrations is due to the growth of particles to observable sizes, not the nucleation process itself. An analysis of the timescales for growth showed that coagulation may be important immediately after the particles have nucleated but its effectiveness reduces as number concentration falls. Conversely, growth by condensation is initially slow due to the Kelvin effect but increases in importance as the particles reach observable sizes.
\end{abstract}

\section{Introduction}

Ultrafine aerosol particles, between 3 and $10 \mathrm{~nm}$ diameter, provide an important source of new aerosol particles in the atmosphere; however, much uncertainty surrounds their formation and growth. Observations of these particles have now been made in a number of different environments including the remote marine boundary layer [Covert et al., 1992], coastal locations [Allen et al., 1999; O'Dowd et al., 1999], forests [(Mäkelä et al., 1997], remote continental sites [Weber et al., 1997] and the free troposphere [Clarke, 1992]. In all cases the presence of these particles is sporadic, occurring in events or bursts lasting from several minutes to a few hours, and only occurs during daylight, implying the gas precursors are photochemically produced. The data from the coastal sites show the periods of new particle production are often

Now at Physics Department, UMIST, P.O. Box 88, Manchester M60 1QD, England, U.K.

Copyright 2000 by the American Geophysical Union.

Paper number 2000JD900234.

0148-0227/00/2000JD900234\$09.00 correlated with UV flux and low tides. A postulated source of precursors is the macroalgae in the intertidal zone; however, the formation processes and the species involved remain unknown. Grennfell et al. [1999] used a mass balance approach to show that the hydroxyl radical initiated oxidation of di-methyl sulphide, emitted from biota in the intertidal zone, could not explain the amount of material present. They were unable to explain the phenomenon. However, this approach assumes that all of the observed ultrafine particle mass was produced in the intertidal zone. O'Dowd et al. [1999] calculated the gas phase sulphuric acid concentration and showed that it displays a coherence with ultrafine particles. The concentrations were not, however, sufficient to explain nucleation by binary $\mathrm{H}_{2} \mathrm{SO}_{4}-\mathrm{H}_{2} \mathrm{O}$, and a ternary mechanism, possibly involving $\mathrm{NH}_{3}$, is proposed. Even so, O'Dowd et al. argue a fourth species, emitted from the intertidal zone, is required to grow the particles to observable sizes.

Recent experiments in the background marine environment [Weber et al., 1995], at a clean continental site [Weber et al., 1997], and over the remote Pacific Ocean [Clarke et al., 1998; Weber et al., 1998] have combined ultrafine particle measurements and direct measurements of gas phase sulphuric acid and the hydroxyl radical. These papers have recently been compared and reviewed by Weber et al. [1999]. 
They conclude that large nucleation events are found exclusively in regions of enhanced sulphuric acid vapor concentrations (up to $5 \times 10^{7}$ molecules $\mathrm{cm}^{-3}$ ). They compared their results with model predictions of binary nucleation and showed that at higher altitudes in the troposphere, colder temperatures enhance the model predictions of $\mathrm{H}_{2} \mathrm{SO}_{4}-\mathrm{H}_{2} \mathrm{O}$ nucleation and result in broad agreement with the measured rates. Close to the surface, model predictions of nucleation rates are many orders of magnitude slower than those inferred from measurements. They provide some evidence that ammonia is involved in a ternary process that can achieve nucleation at much lower levels of sulphuric acid vapor.

In the urban background of Helsinki, Hämeri et al. [1996] observed large concentrations of new particles with diameters less than $10 \mathrm{~nm}$. They were unable to link these observations to a source. Williams et al. [1998] made ultrafine particle measurements in Manchester, United Kingdom, and observed large concentrations of 3 to $5 \mathrm{~nm}$ particles and growth through the mode. These particles correlated strongly with $\mathrm{SO}_{2}$, implicating sulphuric acid vapor is involved in the formation of these particles.

Easter and Peters [1994] have argued that as the nucleation rate is extremely sensitive to changes in temperature, relative humidity and the relative acidity of sulphuric acid vapor, mixing processes, and turbulence greatly enhance ultrafine particle formation. They showed that large scale variations, caused by temperature fluctuations of 1 to $2 \mathrm{~K}$ over 1 hour induced by large eddies or waves, could enhance the binary nucleation rate by over an order of magnitude. The rapid ascent of air under convective conditions may also induce similar effects. Smaller-scale fluctuations caused by turbulence were also modeled by Easter and Peters [1994], and increases in the nucleation rate of up to a factor of 70 were predicted for a well-mixed boundary layer. Nilsson and Kulmala [1998] discuss this previous work and outline cases where larger-scale mixing may also enhance nucleation.

In our work, ultrafine particle measurements were made at a coastal location, and their presence was linked to precursor species. In contrast to the measurements of O'Dowd et al. [1999], made at Mace Head, Ireland, there are no exposed macroalgae in the intertidal zone at the site. The presence of ultrafine particles in maritime conditions would therefore indicate that gas-to-particle conversion processes are taking place in the marine boundary layer over open water. In addition, new particle processes in rural conditions typical of much of the United Kingdom were also investigated. In southerly and southwesterly directions the site is representative of much of the rural United Kingdom and also experiences long-range transport of aged polluted air from central Europe. These different scenarios were used to investigate the formation of new particles from the gas phase in a wide range of conditions.

Previous measurements of ultrafine particles have used either two particle counters with different size cuts [e.g., O'Dowd et al., 1999] or pulse height analysis with a single counter [e.g., Saros et al., 1996]. In the former case the counted particles cover a range of particle sizes and so represent particles with different time histories. Here we use a differential mobility analyzer, fixed at one size, as an inlet to a particle counter. This method allows us to observe particles of a single size at high temporal resolution. In addition to the measurements of ultrafine particles and their precursors, the role of turbulence and mixing is investigated by comparing rapid measurements of ultrafine particles with turbulence parameters.

\section{Methodology}

The experiment took place at the Weybourne Atmospheric Observatory on the north coast of Norfolk, United Kingdom $\left(52.951^{\circ} \mathrm{N}, 1.125^{\circ} \mathrm{E}\right)$ from June 14 to 30,1998 (Figure 1). A full description of the site is given by Penkett et al. [1999]. The observatory lies within $100 \mathrm{~m}$ of the coastline to the north at a height of $15 \mathrm{~m}$ above sea level on grassland sloping down to a pebble sea defence. In northerly wind directions air, often from north of the Arctic Circle, advects over the North Sea directly to the station. The shoreline has no significant tidal zone, and incoming marine air is unlikely to be affected by emissions from the near field. To the south and west, Weybourne is surrounded by flat arable land and is well-removed from immediate local sources. When sampling air from these sectors the location is characteristic of much of the rural United Kingdom and is several hundred kilometers downwind of the large conurbations of London $(190 \mathrm{~km})$ and Birmingham $(250 \mathrm{~km})$. Most of the largest point sources of $\mathrm{SO}_{2}$ in the United Kingdom are located approximately $150 \mathrm{~km}$ to the west and northwest of the site. Trace gas analyzers are located in the main building and are sampled from a $10 \mathrm{~m}$ tall Pyrex glass sampling stack. The particle sizing instrumentation was housed in a mobile laboratory immediately adjacent to the main laboratory, and was sampled through a $3 \mathrm{~m}$ tall $1 / 2$ inch diameter inlet.

Particle size distributions in the range $3 \mathrm{~nm}$ to $450 \mathrm{~nm}$ diameter were measured using a Differential Mobility Particle Sizing (DMPS) system that has been constructed by the Physics department at University of Manchester Institute of Science and Technology and is based on the Vienna design [Winkelmayr et al., 1991]. The DMPS was composed of two differential mobility analyzers (DMAs). The largest had a central rod length of $28 \mathrm{~cm}$, was coupled to Thermo Systems Inc. (TSI) 3010 condensation particle counter (CPC), and measured particles between 20 and $450 \mathrm{~nm}$ diameter. The second DMA had a central rod length of $11 \mathrm{~cm}$, was coupled to a TSI 3025 condensation particle counter, and measured particles between 3 and $20 \mathrm{~nm}$ diameter. The sample flows of the short and long DMAs were set to 1.5 and $11 \mathrm{~min}^{-1}$, respectively, and the sheath air flows to 10 times the sample flow in each case. The voltages on the DMAs were incremented so that in total 52 size channels were retrieved every 8 min. The DMA had a triangular transfer function, whose base width was approximately $5 \%$ of the selected diameter, and that had a $5 \%$ uncertainty in midpoint diameter. The inversion procedure was a Newton-Raphson iteration of Stokes' law in terms of the diameter for a given voltage and set parameters of the DMA [Williams, 1999]. The efficiency of DMAs of this type have been estimated empirically by Birmilli et al. [1997]. Number concentrations of larger aerosol particles (100 nm to $3 \mu \mathrm{m}$ diameter) were measured as a function of their size using an optical scattering probe (ASASP-X). The ASASP-X sizes particles into 31 channels and has a total count accuracy of $10 \%$.

Full size distributions were retrieved every $10 \mathrm{~min}$ throughout the experiment. However, ultrafine particle concentrations can vary rapidly over very short timescales as their 


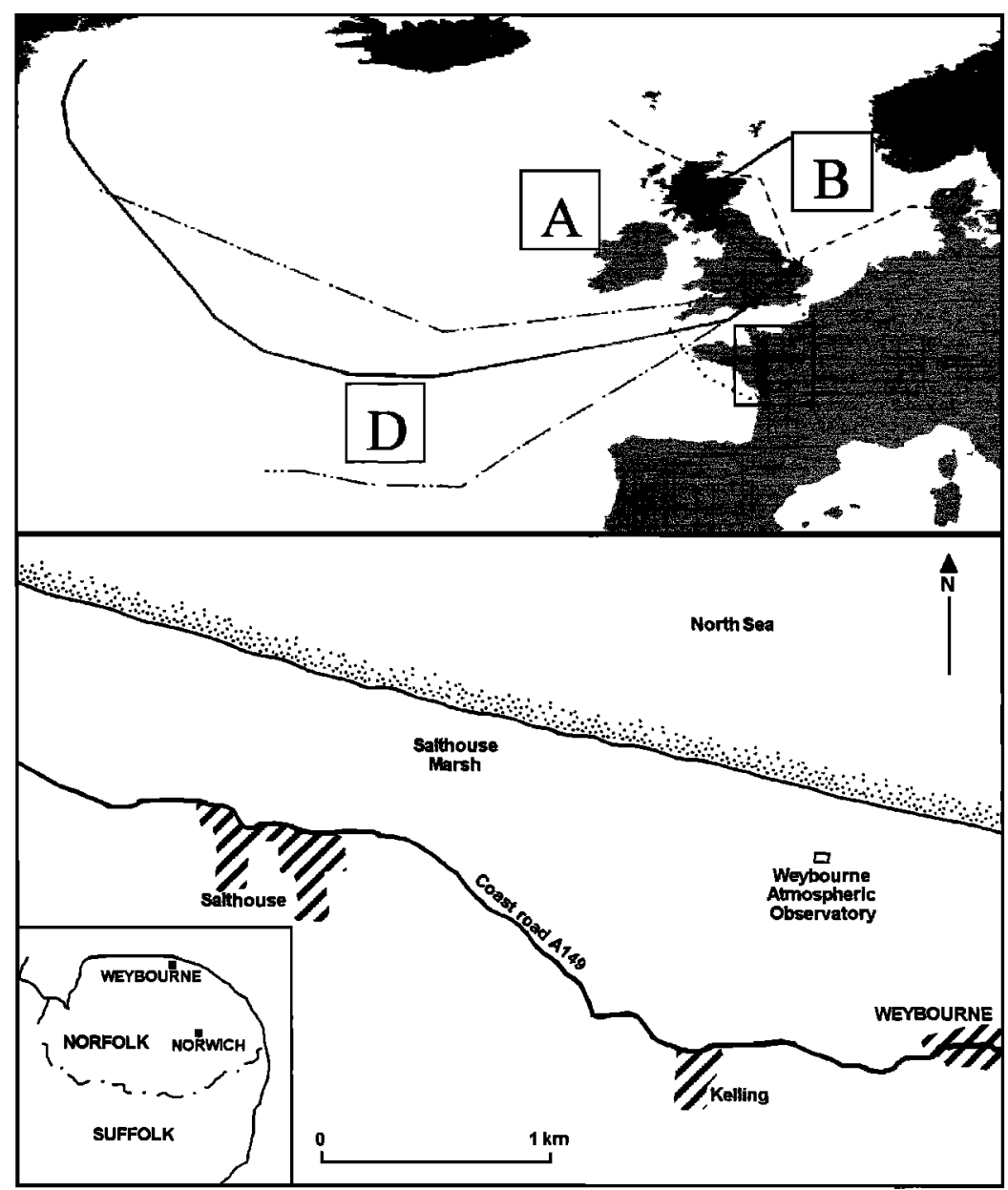

Figure 1. (top) Western Europe and the back trajectory sectors arriving at Weybourne throughout the duration of the experiment. (bottom) The location of the observatory close to the coast and over $1 \mathrm{~km}$ distant from the small villages along the coast road. The location of Weybourne on the north Norfolk coast is shown in the inset.

lifetimes are very short. To investigate these fluctuations, two additional Differential Mobility Analyzers were set up to continuously measure $5 \mathrm{~nm}$ and $20 \mathrm{~nm}$ diameter particles with a time response of $1 \mathrm{~s}$. This approach was used in preference to the differencing method because unlike the latter it provides information at a single size with a narrow transfer function of typically only $0.25 \mathrm{~nm}$ full width at $5 \mathrm{~nm}$. The differencing technique counts the number of particles between the lowest size cuts of two different CPCs, usually $3 \mathrm{~nm}$ and $7 \mathrm{~nm}$ in the case of the most commonly used TSI 3025 and 3022 instruments. However, the growth times of 3 and $7 \mathrm{~nm}$ particles are considerably different. Clearly, the presence of a large number of $7 \mathrm{~nm}$ diameter particles and no $3 \mathrm{~nm}$ particles is not an indication of immediate new particle formation, yet this will be indistinguishable from such an event by the differencing method. Furthermore, retrieving information on the 3 to $7 \mathrm{~nm}$ range by differencing between two large numbers is not sensitive when background concentrations are high relative to the ultrafine number concentrations. The rapid measurement of $5 \mathrm{~nm}$ particles after classifying with a DMA in combination with complete size distribution measurements at lower temporal resolution information yields more information about the behavior of small particles than differencing alone. However, the data from the single sized DMA need to be averaged to $1 \mathrm{~min}$ to overcome the poor counting statistics at these sizes.

The important chemical precursors and physical parameters relevant to new particle formation were also measured. $\mathrm{SO}_{2}$ was monitored using a Teco $42 \mathrm{~S}$ to provide an estimate of the sulphuric acid gas concentration, a likely precursor due to its extremely low saturated vapor pressure. The Teco $42 \mathrm{~S}$ has a lower detection limit of $0.3 \mathrm{ppbv}$ and a precision of $1 \%$. The influence of photolytic processes on the formation of new particles was investigated using radiometric measurements of the photolysis rate of $\mathrm{NO}_{2}, j_{\mathrm{NO} 2}$. The hydroxyl radical is the main oxidant involved in the formation of aerosol precursor gases, and its primary production rate can be found from the ozone concentration and its rate of photolysis to the excited $\mathrm{O}\left({ }^{1} D\right)$ state. This can be estimated by scaling $j_{\mathrm{NO} 2}$ using the clear-sky ratio $j_{\mathrm{O}(1 D)} ; j_{\mathrm{NO} 2}$ for any given time of day. This approximation has been validated during periods when a $j_{\mathrm{O}(1 D)}$ radiometer was available and was shown to be accurate to $25 \%$. Measurements of ozone were made using a Teco 49 with a precision of 1 ppbv. All of the above data were recorded at a time resolution of at most 1 min so that processes influencing the behavior of new particles could be correlated with the fast $5 \mathrm{~nm}$ particle measurements. In addition to the chemical measurements a full range of meteorological pa- 
rameters was measured using an automatic weather station mounted at the top of the $10 \mathrm{~m}$ sampling tower. Lastly, a sonic anemometer (Gill Solent model N1012R) and a fast response UV hygrometer (Campbell Model $\mathrm{KH}_{2} \mathrm{O}$ ) were mounted on a separate $10 \mathrm{~m}$ mast to measure the three wind components, temperature, and water vapor at $20 \mathrm{~Hz}$. Sensible and latent heat fluxes were calculated from these measurements to investigate the role of turbulence in new particle formation. The sonic anemometer resolves the 3 orthogonal wind components with a resolution of $+/-0.01 \mathrm{~cm} \mathrm{~s}^{-1}$ and has an uncertainty of $1 \%$.

\section{Results}

\subsection{General}

The hourly averaged aerosol size distributions taken throughout the campaign are presented in Plate 1 in the form of a contour plot of $d N / d \log D_{p}$. The general characteristics of the aerosol size distributions change markedly throughout the experiment. Figure 2 shows the temperature, radiation, and $\mathrm{SO}_{2}$ time series throughout the experimental period, together with the aerosol surface area and the transfer coefficient to preexisting aerosol surfaces, $k_{\text {loss }}$ (see equation (2)). Also shown in Figure 2 is the time series of hourly averaged $5 \mathrm{~nm}$ diameter particle concentrations for comparison with the other parameters. There is an increased uncertainty in the calibration of the $\mathrm{SO}_{2}$ data before June 20 , and these data were not used in any subsequent analyses. Back trajectories were calculated using European Centre for Medium Range Weather Forecasts (ECMWF) analyses to arrive at Weybourne at 1200 for each day during the experiment and have been grouped into four broad categories. The spatial extent of each of these groupings is shown in Figure 1, and periods during which Weybourne experienced air of these types are identified in Figure 2. Each of the parameters shown in Figure 2 can affect the formation of new particles in the atmosphere; however, because many processes are occurring simultaneously, there is unlikely to be a straightforward relationship between any individual parameter and the measurements of 5 $\mathrm{nm}$ particles. To assess the extent to which a relationship between these parameters and $5 \mathrm{~nm}$ diameter particle number concentration $N_{5}$ exists, the Spearman rank correlation coefficient $R_{\mathrm{s}}$ was calculated for each variable and $N_{5}$ for daytime periods only. The ranks of variables, rather than the variables themselves, are used to calculate $R_{\mathrm{s}}$ as the rank of a distribution is normally distributed even though the variable itself may not be. The $R_{s}$ values for temperature, radiation, $\mathrm{SO}_{2}$, $k_{\text {loss }}$, and aerosol surface area are $5 \times 10^{-3}, 0.4,0.37,-0.3$, and 0.35 . These data show a link between radiation and $\mathrm{SO}_{2}$, and $\mathrm{N}_{5}$, most likely from their role in the photochemical production of $\mathrm{H}_{2} \mathrm{SO}_{4}$ precursor material. Aerosol surface area and $N_{5}$ are negatively related as a result of preexisting surfaces competing for precursor with nucleation and growth of new particles. Similar analyses have been performed by Weber et al. [1997] at a remote continental site in the United States. Our results show strong similarities with this earlier work, which was performed at a much cleaner site and which sampled predominately free tropospheric air.

June 15 and 16 were the only days during the experiment when marine air from the north was advected over the North Sea to the observatory and are identified as sector B in Figure 1. Both days were overcast and are characterized by a nearly constant air temperature of $12^{\circ} \mathrm{C}$ and very low $\mathrm{SO}_{2}$ concentrations at or below the detection limit of the instrument. The aerosol number concentrations during this period were typically 2400 particles $\mathrm{cm}^{-3}$, the lowest during the experiment; however, the aerosol surface area was greater than later in the experiment due largely to an increased number of accumulation and coarse mode particles. The measurements provided no evidence for new particle formation in contrast to the experiments conducted at Mace Head [O'Dowd et al., 1999] where there is a large source of precursor from marine biota in the intertidal zone.

For the remainder of the experiment the site experienced air advected over land from the south and west. However, it is clear from both the back trajectory analysis in Figure 1 and the trace gas and meteorological data in Figure 2 that there was considerable variability in the type and composition of the air arriving at Weybourne. In particular, the back trajectory analysis shows that cyclonic conditions, advecting Atlantic air over the United Kingdom, prevailed on most days from June 17 to 30 (sectors A and D). The exception to this was a 2 day period on June 20 and 21 when anticyclonic conditions delivered air from the south over continental Europe (sector C).

During June 20 and 21 the air arriving at the measurement site was much warmer than that experienced on other days during the experiment, varying between $16^{\circ}$ and $25^{\circ} \mathrm{C}$. There was considerable cumulus activity on June 20 but very little cloud cover on June 21. The air arriving at Weybourne had spent at least the last 5 days over continental Europe, and as a result $\mathrm{SO}_{2}$ concentrations were enhanced for prolonged periods. High solar flux and $\mathrm{SO}_{2}$ concentrations will lead to an increase in the rate of production of sulphuric acid and potentially a source of material for ultrafine particle formation. However, large increases in the aerosol surface area and hence in the uptake coefficient $k_{\text {loss }}$ were also observed during this period, increasing the sink for sulphuric acid onto preexisting surfaces. Enhanced aerosol concentrations during this period can be identified easily in Plate 1 by the considerably enhanced peak aerosol number concentrations occurring at larger sizes (up to $100 \mathrm{~nm}$ ) than at other times during the experiment. These properties of the aerosol are as a result of considerable processing during several days' transport from central and southern Europe. This is compounded by reports of desert dust falls in parts of the United Kingdom, implying that long-range transport from the Sahara was experienced during these 2 days [Weather Log, 1998]. Both the increased particle number and also their large size enhanced the surface area of the aerosol population and so provided a more efficient sink for precursor material, reducing the potential for new particle formation.

For the remainder of the experiment, air was arriving at Weybourne from sectors A and D. In both these cases the air masses were cyclonic and had crossed the United Kingdom in less than a day from the Atlantic Ocean. However, recent formation of particles, indicated in Figure 2 by the $5 \mathrm{~nm}$ diameter number concentration time series, does not appear to occur on all of these days but is clearly evident on June 17 , 22,25 , and 27-30. A comparison of the back trajectories on these days with those when new particles were not seen, June $18,19,23,24$ and 26 , shows a distinct difference between the days when new particles were and were not observed, identified as sectors A and D, respectively. Although all the back 


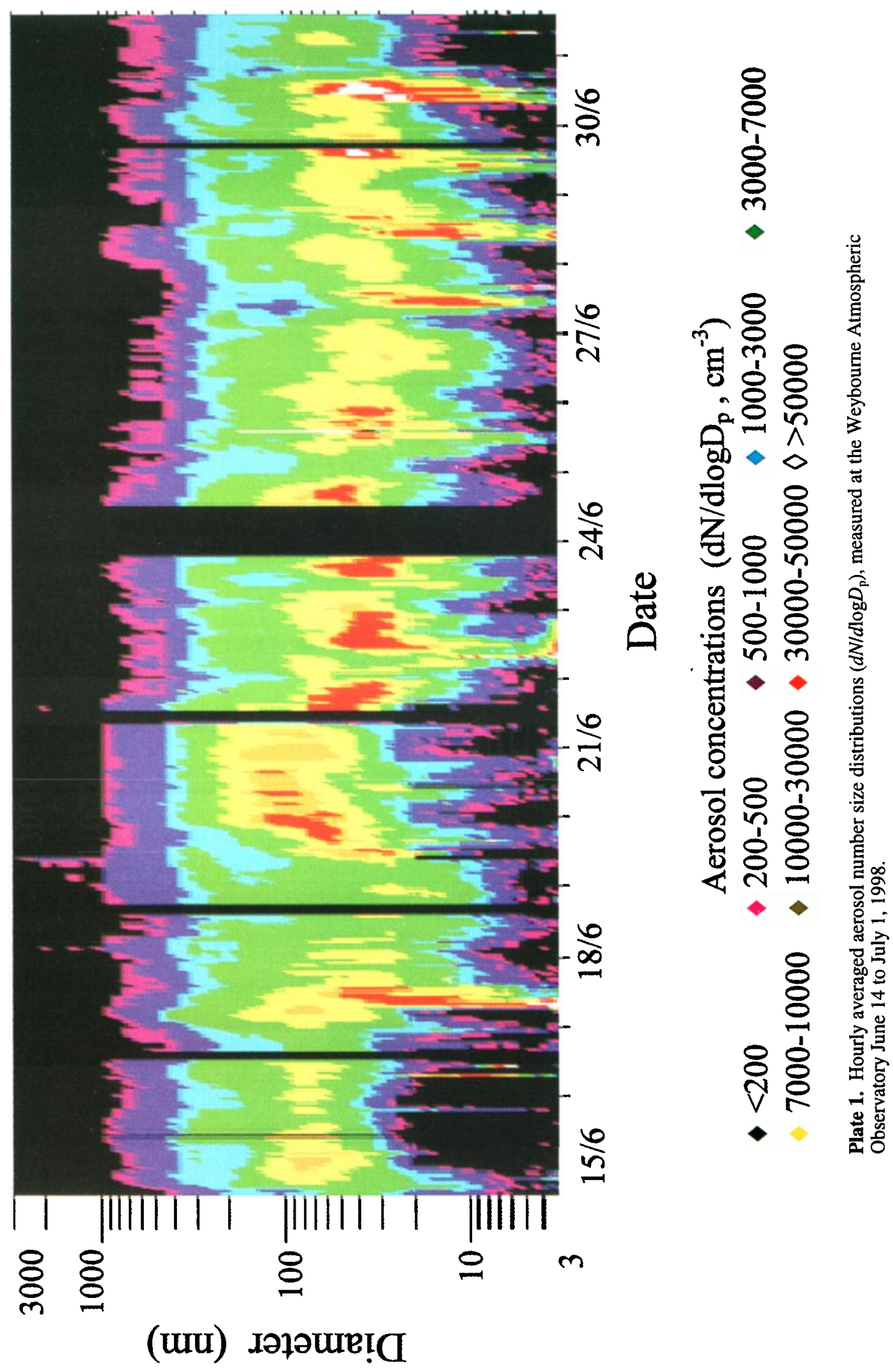



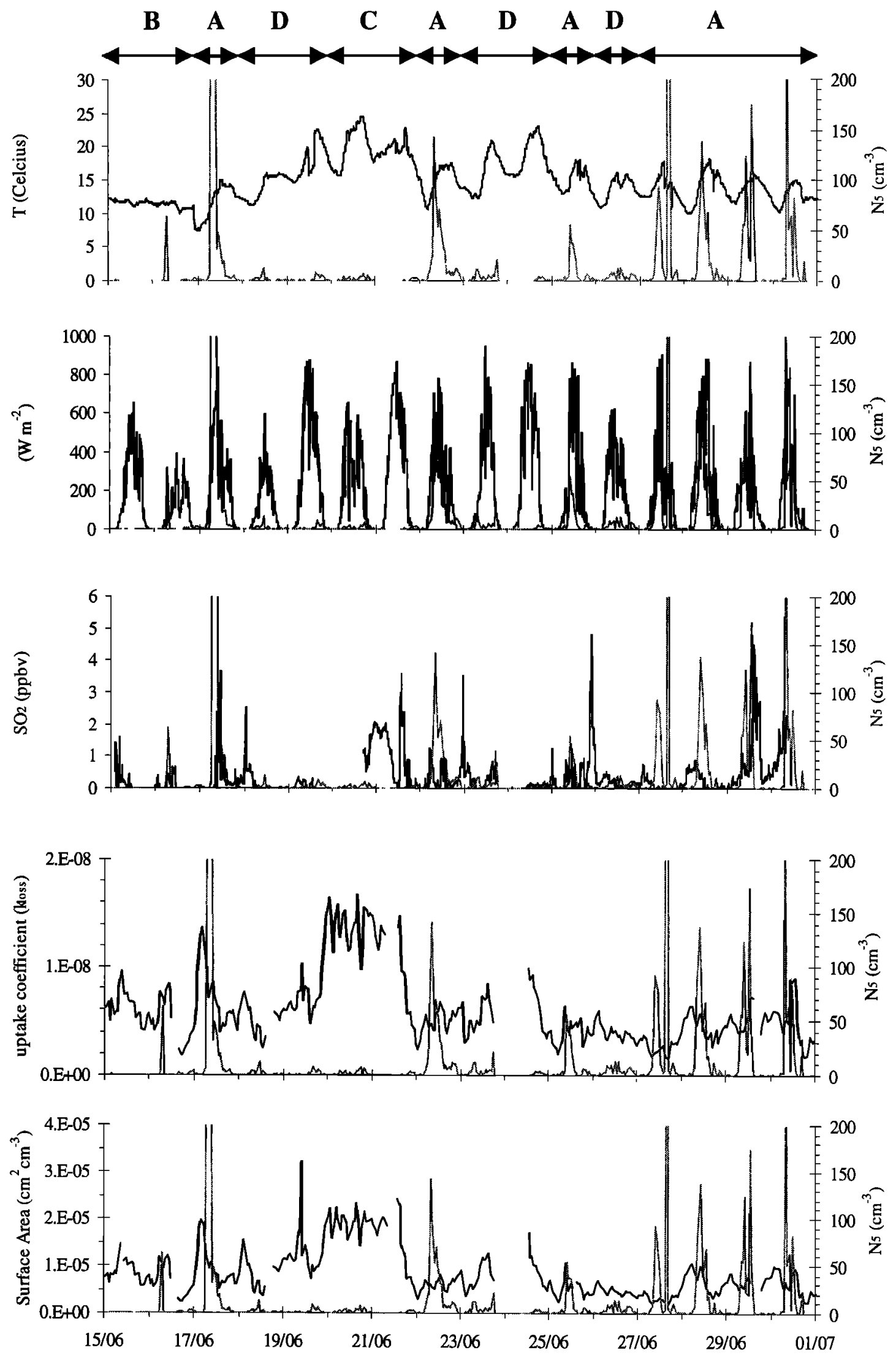

Figure 2. Temperature, radiation, sulphur dioxide, uptake coefficient, and aerosol surface area time series at the Weybourne Atmospheric Observatory from June 14 to July 1, 1998. The transfer coefficient $k_{\text {loss }}$ was calculated from the size distribution measurements using the relation given by Schwartz [1986, equation (2)]. The light grey time series shows the number concentration of $5 \mathrm{~nm}$ particles. Periods when the site experienced air from the different sectors shown in Figure 1 are also indicated: A, westerly new particle production; B, marine; C, continental; D, westerly no new particle production. 
trajectories in both groups are cyclonic, those grouped into sector A are generally from the west and cross the north of England and Scotland; those grouped into sector D traverse the south of England and are generally from more southerly latitudes in the Atlantic Ocean.

The meteorological, gas, and aerosol characteristics of these two groups are also significantly different. In both cases the air temperature increased throughout the morning and early afternoon, although days in group $\mathrm{D}$ increased from $15^{\circ}$ to $20^{\circ} \mathrm{C}$, whereas those in group $\mathrm{A}$ were somewhat colder, $10^{\circ}$ to $15^{\circ} \mathrm{C}$. June 26 , a type D day, was, however, similar in temperature to those of type $\mathrm{A}$. $\mathrm{SO}_{2}$ mixing ratios on group $\mathrm{D}$ days were low, usually less than $0.5 \mathrm{ppbv}$ and often below the detection limit of the instrument. In contrast, $\mathrm{SO}_{2}$ mixing ratios on group A days were very variable but generally above $1 \mathrm{ppbv}$ in the moming periods. The variation in the $\mathrm{SO}_{2}$ concentration on timescales of 1 to 2 hours correlates with changes in the local wind direction and suggests that the site was in the plume of a large source several tens of kilometers distant. The exception to this was June 27 when the $\mathrm{SO}_{2}$ concentration was between 0.5 and $1 \mathrm{ppbv}$. Aerosol surface areas on days when new particles were observed (type A) were the lowest experienced during the experiment and twice as low as those observed on type D days. Again, June 26 is the exception and displays surface area characteristics similar to those on days when new particles were observed.

The differences in temperature, $\mathrm{SO}_{2}$, and aerosol surface area between groups $\mathrm{A}$ and $\mathrm{D}$ all favor the formation of new particles in the former group. A reduction in temperature of $5^{\circ} \mathrm{C}$ will increase the rate of binary nucleation by over an order of magnitude [Easter and Peters, 1994] and will also increase the condensation rate of material onto recently formed particles (Figure 7), though this effect is only slight. The increased concentrations of $\mathrm{SO}_{2}$ on type $\mathrm{A}$ days provide an increased source of $\mathrm{H}_{2} \mathrm{SO}_{4}$, and reduced aerosol surface areas provide a reduced sink. Note also that several periods of increased $\mathrm{SO}_{2}$ above 2 ppbv occurred either at night or during periods of very high aerosol surface area and no new particles were observed. Clearly a combination of factors is required. The largest point sources of $\mathrm{SO}_{2}$ in the United Kingdom are located in an area to the west and northwest of Weybourne approximately $100 \mathrm{~km}$ distant. Both the back trajectory analysis and the variability in the $\mathrm{SO}_{2}$ suggest that this area is the likely source of precursor material.

\subsection{Formation and Behavior of Ultrafine Particles}

When ultrafine particles were observed (type A), similar behavior was seen on all of the days (Plate 1 and Figure 2). A large increase in $3 \mathrm{~nm}$ diameter particles was observed at around 0900 , throughout the morning the modal diameter of these particles increased rapidly, and by 1100 it was contributing to the peak of the Aitken mode at $20 \mathrm{~nm}$. On most days when new particle production was observed, large increases in ultrafine mode aerosol were preceded by reductions in the preexisting particle population. This can be seen both in the contour plot and also in the time series of aerosol surface area and $5 \mathrm{~nm}$ diameter particle number concentration. One explanation of the reduction in preexisting aerosol concentration is the breakdown of a low-level nocturnal inversion early in the morning, mixing cleaner air from aloft with the aerosolrich air trapped near the surface overnight. This hypothesis is supported by turbulence and sensible heat flux measurements that show a sharp change from stable to unstable conditions around this time on each of these days. Although this mixing may enhance new particle formation also, the data cannot identify whether this may be the cause of the large increases of $5 \mathrm{~nm}$ particles around $60 \mathrm{~min}$ later.

By early afternoon the number of $3 \mathrm{~nm}$ particles had greatly diminished, and in most cases this very small particle mode reduced in both size and number and no longer contributed to the Aitken mode above $10 \mathrm{~nm}$. The peak in the Aitken mode fraction steadily increased in size throughout the day, reaching $50 \mathrm{~nm}$ by the evening, and the number concentration diminished through coagulation and dilution. The Aitken mode continued to reduce in number, but the mode increased in diameter through the night. Although the general behavior of the ultrafine particles was similar on all of these days, there are distinct differences between them. Since the experiment was conducted in a Eulerian framework, the variations in the ultrafine mode aerosol throughout the day may only be interpreted as growth from the freshly nucleated aerosol if the air mass was spatially homogeneous throughout the period. This may be the case in this study as on many days the upper Aitken and accumulation mode aerosol concentrations do not change substantially throughout the day (Plate 1 and Figure 3).

Figure 3 shows four sets of five size distribution spectra measured using the DMPS system during periods of high ultrafine particle concentration on June $17,22,28$, and 30 . Different behavior is observed on each of these days. On June 17 very large concentrations of $3 \mathrm{~nm}$ particles are observed to occur as early as 0630 , and the mode increases in size and $30 \mathrm{~min}$ to 1 hour later is combined with the Aitken mode. The concentration of $3 \mathrm{~nm}$ particles diminishes by midday, but the modal diameter increases throughout the afternoon (Plate 1). On June 22, similar large concentrations of $3 \mathrm{~nm}$ particles are observed to occur by 0700 , yet, although the number of these particles increases throughout the morning, there is little evidence for these particles affecting the Aitken mode. The concentration of $3 \mathrm{~nm}$ particles declines after midday, and there appears to be no increase in particle concentration at sizes above $5 \mathrm{~nm}$. However, a separate mode larger than $10 \mathrm{~nm}$, peaking at around $20 \mathrm{~nm}$ (Plate 1), was observed shortly before midday and whose modal diameter increased throughout the afternoon. The appearance of these particles appears to be unrelated to the $3 \mathrm{~nm}$ particles observed earlier in the day, indicating that these particles were formed separately some distance upwind. A rapid increase of $3 \mathrm{~nm}$ diameter particles was again observed at 0800 on June 28 , but on this day $10 \mathrm{~nm}$ particles were seen to increase at the same time. More $3 \mathrm{~nm}$ particles were observed than either 5 or $10 \mathrm{~nm}$ particles, but like June 22 there were more $10 \mathrm{~nm}$ particles than those of $5 \mathrm{~nm}$ diameter throughout the day. The appearance of the $3 \mathrm{~nm}$ particles is not directly related to the large increase in $10 \mathrm{~nm}$ particles and implies that there are two processes occurring. On June 30 a much lower concentration of $3 \mathrm{~nm}$ particles was observed than on other days, but a large mode centered at $10 \mathrm{~nm}$ was observed suddenly after 0800 . The modal diameter of these particles appears to increase with time and merge with the Aitken mode throughout the afternoon (Plate 1). Again, the $3 \mathrm{~nm}$ particles are no longer present after midday. The sudden appearance of a new mode, centered at $10 \mathrm{~nm}$, without a preceding increase in smaller particles suggests that ultrafine particles on June 30 appeared to have been formed away from the measuring 

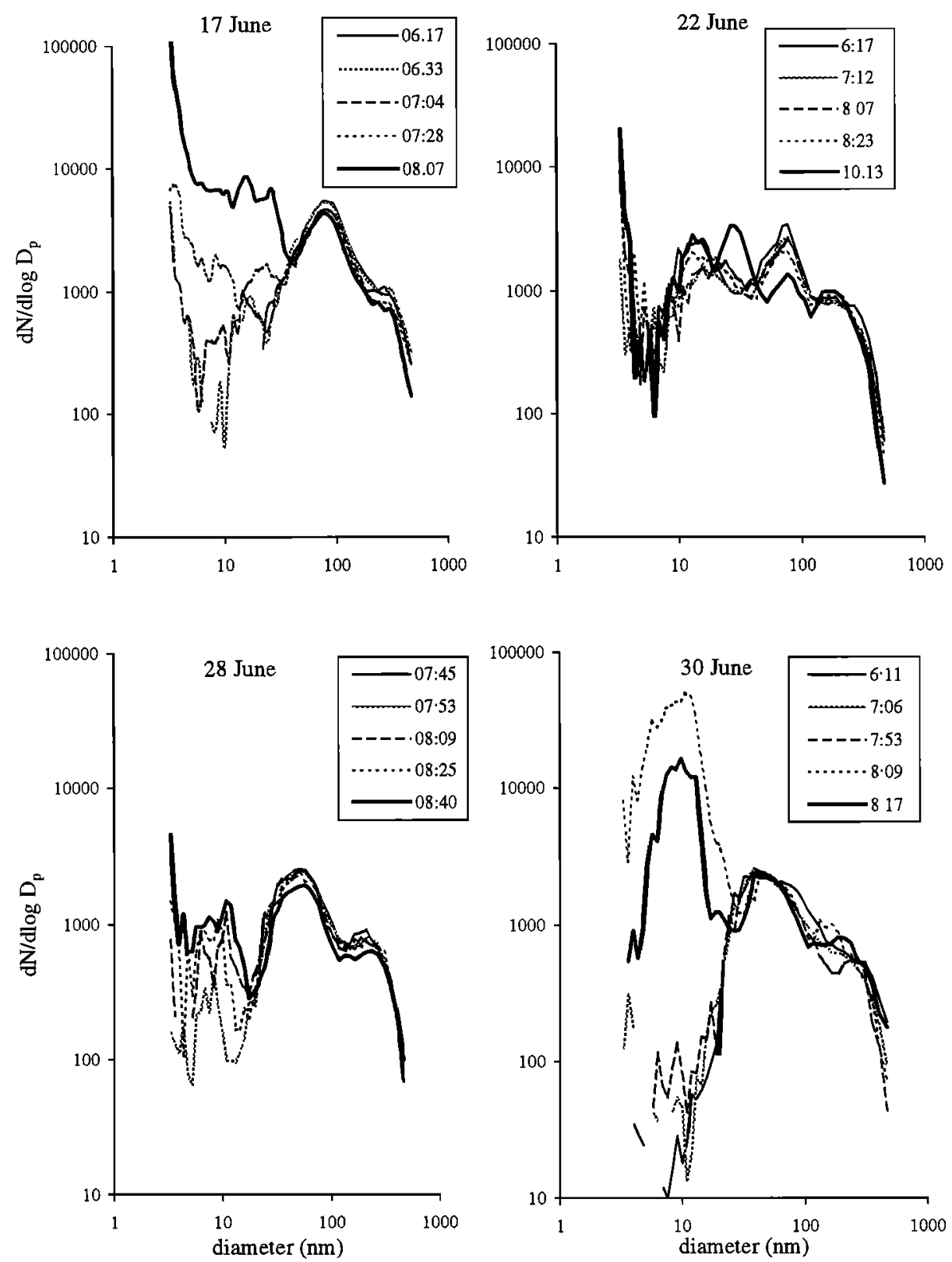

Figure 3. Examples from four separate days of particle number distributions measured using the DMPS system during the periods when enhanced ultrafine particle concentrations were observed. On each day, five spectra are shown to illustrate the development of the ultrafine particle population through the morning. The 4 days show distinctly different behavior.

station and transported to the site. No new particle formation appears to be occurring in situ. Measuring new particle concentrations using either the difference between two CPCs, or a single, fixed size DMA alone will not discriminate between these different events. Size distributions must also be measured.

\subsection{The Role of Turbulence}

Clouds have been implicated in new particle formation in the remote marine environment [Clarke et al., 1998; Radke and Hobbs, 1991], and freshly nucleated particles have often been observed in subsiding air masses [Covert et al., 1996]. Easter and Peters [1994] and Nilsson and Kulmala [1998] have shown in modeling studies that the mixing and turbu- lence may well increase binary nucleation rates by an order of magnitude or more. To investigate the role of mixing in the formation of new particles, a sonic anemometer was used throughout the Weybourne experiment to retrieve rapid measurements of wind velocity in three dimensions and temperature. The presence of large concentrations of $5 \mathrm{~nm}$ particles followed the onset of convection in the morning by between $30 \mathrm{~min}$ and an hour, and their disappearance in midafternoon coincided with a marked reduction in heat flux, the covariance of vertical wind speed and temperature on every day. Formation of particles directly from the gas phase is likely to be a very strong function of temperature, and enhanced mixing in the morning may promote new particle formation by rapid lifting and cooling of air, rich in precursor material, that is close to the surface [Easter and Peters, 1994; Nilsson and 


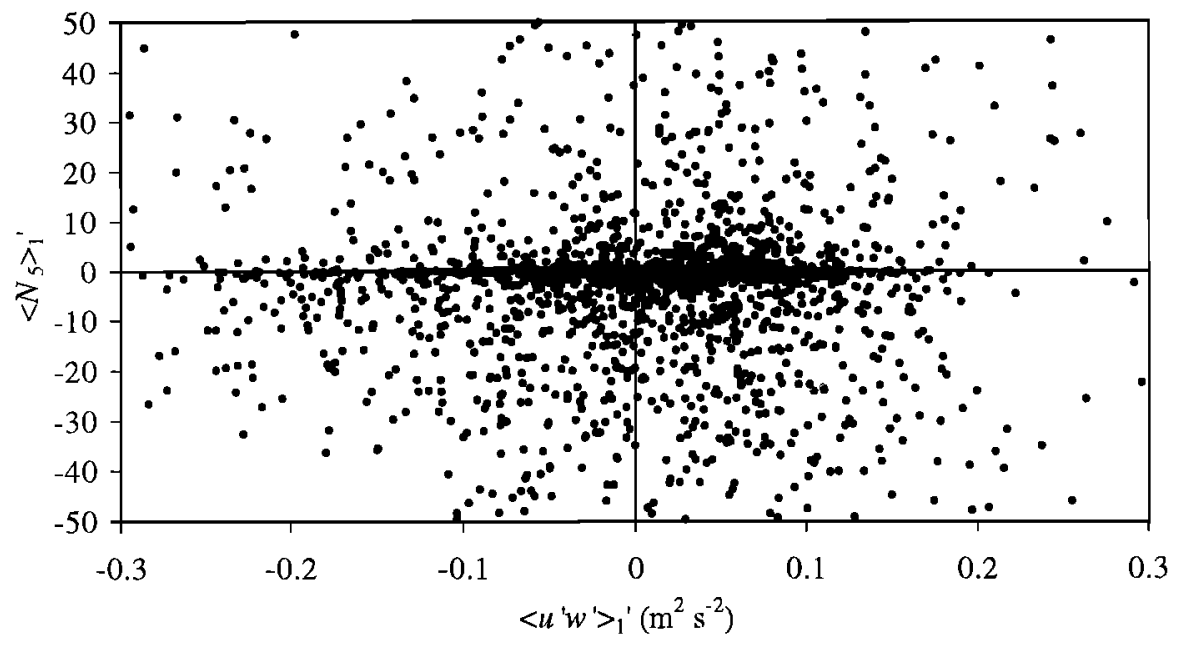

Figure 4. Scatterplot of $\left\langle u^{\prime} w^{\prime}\right\rangle_{1}^{\prime}$ and $\left\langle N_{5}\right\rangle_{1}^{\prime}$, the deviations of 1 min averages of $u^{\prime} w^{\prime}$ and 5 nm particle measurements from their respective hourly running means. The data, taken from the whole experiment, show no correlation indicating that $5 \mathrm{~nm}$ particles are well mixed in the lower boundary layer on these timescales.

Kulmala, 1998]. Broken cumulus clouds are present on most mornings when new particles are observed above the observing station. However, surface heating is largely controlled by incoming short wave radiation, and this also drives hydroxyl radical formation through UV photolysis of ozone. As the hydroxyl radical is central to the formation of low volatility gas phase oxidation products in the atmosphere, it is not obvious whether the association between heat flux and new particles is due to microphysical or chemical processes.

To discriminate between these effects, the $1 \mathrm{~min}$ time averaged covariance of the horizontal and vertical components of the wind, $\left\langle u^{\prime} w^{\prime}\right\rangle_{1}$, was calculated and compared with the 1 min averaged $5 \mathrm{~nm}$ particle number concentration, $\left\langle N_{5}\right\rangle_{1}$. The parameter $\left\langle u^{\prime} w^{\prime}\right\rangle_{1}$ is the minute averaged kinematic momentum flux and represents the turbulent intensity on timescales of less than $1 \mathrm{~min}$. The absolute magnitudes of both $\left\langle u^{\prime} w^{\prime}\right\rangle_{1}$ and $\left\langle N_{5}\right\rangle_{1}$ will depend on many different and unrelated factors. To explore whether there is link between mixing and new particles overall, trends in both data sets were removed by finding the difference between the instantaneous values of the parameters and their hourly averages, $\left\langle u^{\prime} w^{\prime}\right\rangle_{1}{ }^{\prime}$ and $\left\langle N_{5}\right\rangle_{1}^{\prime}$, respectively. A scatterplot of $\left\langle u^{\prime} w^{\prime}\right\rangle_{1}^{\prime}$, and $\left\langle N_{5}\right\rangle_{1}^{\prime}$ is shown in Figure 4 and includes all the days when new particles were observed. This approach identifies the effects of mixing on timescales of 1 or more min on ultrafine particle concentrations, although it cannot detect whether there is an influence of smaller-scale turbulence effects. The vertical length scales associated with these timescales are of the order of 20 to $60 \mathrm{~m}$, considerably less than the typical daytime boundary layer heights ( 1.5 to $3 \mathrm{~km}$ ) calculated from similarity theory using the surface heat flux [Stull, 1988]. There is clearly no link between the extent of mixing at Weybourne and increases or decreases in $5 \mathrm{~nm}$ particle number concentrations from these measurements. A mean of the minute averaged product $\left\langle u^{\prime} w^{\prime}\right\rangle_{1}{ }^{\prime}\left\langle N_{5}\right\rangle_{1}^{\prime}$ was calculated for the whole campaign and was found to be a factor of 3 less than its standard error. This result confirms that there is no statistical link between mixing and $N_{5}$ in this data set and hence that it is likely that $5 \mathrm{~nm}$ particles are well mixed throughout boundary layer.
However, although there do not appear to be any strong gradients of $N_{5}$ with height in the lower boundary layer, this does not provide any direct evidence of nucleation occurring throughout the boundary layer, though this is one explanation of the observations. Alternatively, if the growth times of nucleated particles to $5 \mathrm{~nm}$ diameter are of the same order as, or longer than the turnover times of air through the boundary layer, then mixing processes will have averaged out any variation in nucleation with height by the time the particles have grown to $5 \mathrm{~nm}$ diameter. In this experiment the timescale for mixing air throughout a $1 \mathrm{~km}$ boundary layer based on our measured turbulence parameters is of the same order, 30 to 90 $\mathrm{min}$, as the particle growth time from nucleation to $5 \mathrm{~nm}$ (see next section). This implies that while the above approach is useful, it is unlikely to yield information on the heterogeneity of nucleation in the boundary layer unless considerably smaller particle sizes are investigated.

\subsection{Precursor Species}

Clearly, if gas to particle conversion processes take place via a first-order phase transition, the atmospheric availability of precursor material must exceed its saturation vapor pressure. A likely precursor gas is sulphuric acid, whose formation rate is determined by the initial hydroxyl radical oxidation of sulphur dioxide (see below). Sulphuric acid-water binary nucleation systems have been studied in considerable detail. A large energy barrier has to be overcome to stabilize the newly formed clusters, and this leads to rates of formation that are too slow to explain field observations at atmospherically realistic sulphuric acid concentrations [Pirjola and Kulmala, 1998; Kulmala et al., 1998; O'Dowd et al., 1999]. However, Coffman and Hegg [1995] modeled the ternary nucleation system $\mathrm{H}_{2} \mathrm{SO}_{4}-\mathrm{H}_{2} \mathrm{O}-\mathrm{NH}_{3}$ and showed that nucleation rates greatly exceed those of binary systems. Their model predicts that the presence of ammonia may lead to the formation of ammonium sulphate or bisulphate particles, where the interactions between $\mathrm{NH}_{4}{ }^{+}$and $\mathrm{HSO}_{4}{ }^{-}$or $\mathrm{SO}_{4}{ }^{2-}$ ions in aqueous solution lead to a suppressed saturation vapor pressure of $\mathrm{H}_{2} \mathrm{SO}_{4}$ compared with pure sulphuric acid particles [Pitzer, 
1979]. This reduces the critical cluster size and nucleation energy barrier and so greatly enhances their initial rate of formation. Ammonia is ubiquitous in the rural environment, and mixing ratios of between 500 parts per trillion by volume (pptv) and 2 ppbv have been observed at Weybourne under conditions similar to those experienced during the experiment. Typical sulphuric acid concentrations range from $10^{5}$ to $10^{7}$ molecules $\mathrm{cm}^{-3}$ [Eisele and Tanner, 1993; Weber et al., 1997] in the clean continental boundary layer. Hence, although the nucleation process may well be ternary, the formation of new particles will be dictated by the $\mathrm{H}_{2} \mathrm{SO}_{4}$ concentration as ammonia is likely to always be in excess. The availability of $\mathrm{H}_{2} \mathrm{SO}_{4}$ will be determined on the one hand by its formation rate in the gas phase and on the other by its removal onto the surfaces of preexisting aerosols.

The measurement of sulphuric acid requires highly specialized instrumentation [e.g., Eisele and Tanner, 1993] that was not available during the Weyboume campaign, so its role in the formation of ultrafine particles was examined using a simple steady state approximation. The formation rate of sulphuric acid in the gas phase is determined by the initial attack of $\mathrm{OH}$ on $\mathrm{SO}_{2}$, which has a rate constant $k_{1}$. The hydroxyl radical concentration can be estimated by assuming that primary production was the only source of $\mathrm{OH}$, $[\mathrm{OH}]=2 \mathrm{j}_{\mathrm{O}(1 D)}\left[\mathrm{O}_{3}\right] / \mathrm{OH}$ losses. Hence the production rate of $\mathrm{H}_{2} \mathrm{SO}_{4}$ is given by $k_{1} j_{\mathrm{O}(1 D)}\left[\mathrm{O}_{3}\right]\left[\mathrm{SO}_{2}\right] / \mathrm{OH}$ losses, and a steady state concentration of $\mathrm{H}_{2} \mathrm{SO}_{4}$ can then be calculated using the loss rate to preexisting aerosol surfaces, $k_{\text {loss. }}$.

$$
\left[\mathrm{H}_{2} \mathrm{SO}_{4}\right]_{\mathrm{ss}}=\frac{k_{1} j_{\mathrm{O}\left({ }^{\prime} D\right)}\left[\mathrm{O}_{3}\right]\left[\mathrm{SO}_{2}\right] / \mathrm{OH} \text { losses }}{k_{\text {loss }}} .
$$

The transfer coefficient for $\mathrm{H}_{2} \mathrm{SO}_{4}$ to preexisting surfaces, $k_{\mathrm{loss}}$, is taken from Schwartz [1986] and was calculated using measured size distributions.

$$
k_{\text {loss }}=\frac{4 \pi}{3} \int_{0}^{\infty}\left(\frac{r^{2}}{3 D_{g}}+\frac{4 r}{3 \gamma c}\right)^{-1} r^{3} \frac{d N}{d \log r} d \log r
$$

where $r$ is the particle radius, $D_{g}$ is the diffusion coefficient of $\mathrm{H}_{2} \mathrm{SO}_{4}, c$ is the molecular speed of the gas, and $N$ is the parti- cle number. The uptake coefficient of sulphuric acid, $\gamma$, is taken to be unity. Jefferson et al. [1997] have measured the uptake coefficient of $\mathrm{H}_{2} \mathrm{SO}_{4}$ onto several substrates and found that $\gamma=0.7$ for inorganic salts, but reduced to 0.3 if an organic film coated these surfaces.

The losses of $\mathrm{OH}$ were not measured during the Weyboume experiment; however, as the concentration of the radical is controlled largely by the concentrations of $\mathrm{NO}_{x}, \mathrm{CO}$, and $\mathrm{CH}_{4}$, they are likely to vary much more slowly with time than the rapid changes in new particle concentration. If the losses of $\mathrm{OH}$ are assumed to be constant, then

$$
\left[\mathrm{H}_{2} \mathrm{SO}_{4}\right] \propto k_{1} j_{\mathrm{O}\left({ }^{\prime} D\right)}\left[\mathrm{O}_{3}\right]\left[\mathrm{SO}_{2}\right] k_{\mathrm{loss}}{ }^{-1}=A_{A}
$$

This relationship is valid over time periods that are shorter than the fluctuations in the $\mathrm{OH}$ losses, but over longer timescales the proportionality constant will vary. However, despite this limitation, the relationship provides a useful way of investigating the influence of sulphuric acid as a precursor to ultrafine particles in rural air at Weybourne.

Figure 5 shows the time series of the $\mathrm{H}_{2} \mathrm{SO}_{4}$ availability, $A_{A}$, calculated using minute averaged data for a single day, June 28,1998 , to illustrate the rapid fluctuations in detail. Also shown in the figure are the minute averages of the fast measurements of $5 \mathrm{~nm}$ particles. The parameter $A_{A}$ is partly controlled by the photolysis of ozone through the $O\left({ }^{1} D\right)$ channel and so rises rapidly as the UV flux increases shortly after 0600 . However, $5 \mathrm{~nm}$ particles are not observed until 0800 , a delay of approximately 1.5 hours. This was typical of all of the days on which increased $5 \mathrm{~nm}$ particle concentrations were observed, the delay times varying from 30 to 90 min. For the remainder of the day the rapid fluctuations of the $5 \mathrm{~nm}$ particles are mirrored by those in the value of $A_{A} . A_{A}$ reduces markedly in the early afternoon, although $j_{\mathrm{O}(1 D)}$ remains high. This is due to a large reduction in the concentration of $\mathrm{SO}_{2}$ at this time and further emphasizes the role of sulphuric acid in the nucleation and growth of ultrafine particles.

Figure 6 shows the relationship between $A_{A}$ and ultrafine particle number concentrations for the period between June 20 and 30 when a reliable calibration for $\mathrm{SO}_{2}$ was available. The figure shows all the data together and also the contribu-

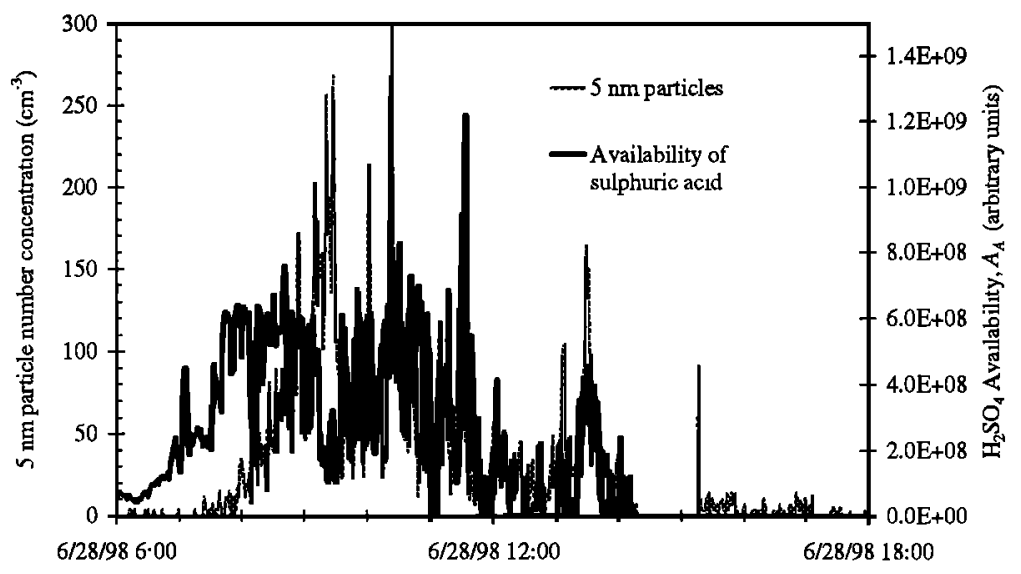

Figure 5. One minute averages of acid availability $A_{A}$ and $5 \mathrm{~nm}$ diameter particles for the daytime of June 28 , 1998. The acid availability scale is arbitrary but emphasises the close correlation between fluctuations in the acid precursor and growth of $5 \mathrm{~nm}$ ultrafine particles. 

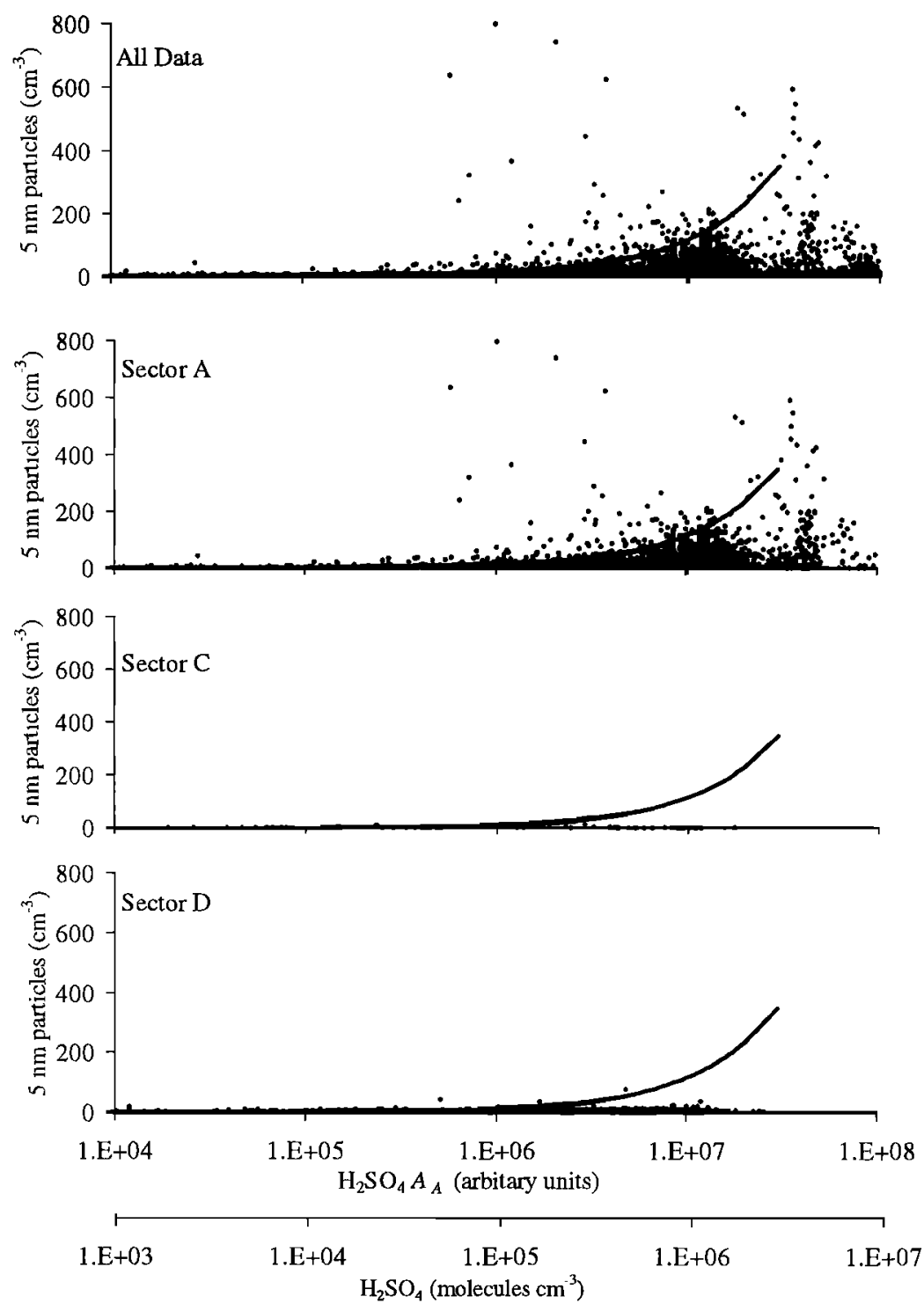

Figure 6. Scatterplots of $\mathrm{H}_{2} \mathrm{SO}_{4}$ acid availability and $5 \mathrm{~nm}$ particle number concentration for the period of June 20 to 30 . The data from each of the three sectors experienced during this period are also shown in separate panels. The solid line is a linear fit to the upper bound of $N_{5}$ as a function of $A_{A}$ and has a slope of $1.2 \times 10^{-5}$. Approximate sulphuric acid concentrations are also shown (see text for details).

tions from each of the sectors A, C, and D. The solid line is linear with a gradient of $1.2 \times 10^{-5}$ and indicates the approximate upper limit to the observed $N_{5}$ for any given $A_{A}$. To illustrate the absolute amounts of $\mathrm{H}_{2} \mathrm{SO}_{4}$ at Weybourne, an approximation has been made from the calculated values of $A_{A}$. This was done by assuming that the maximum $\mathrm{OH}$ concentration observed at Weybourne during this period was $2 \mathrm{x}$ $10^{6}$ molecules $\mathrm{cm}^{-3}$; similar values for the maximum daytime $\mathrm{OH}$ concentration have been measured at Weybourne in the past at this time of year [Forberich et al., 1999]. The ratio of $[\mathrm{OH}]$ to the product of $j_{\mathrm{O}(\mathrm{ID})}\left[\mathrm{O}_{3}\right]$ at solar noon was found to be 0.11 , and this value was used to convert the $A_{A}$ in (3) to a concentration throughout the reminder of the day. Though by no means an accurate representation of sulphuric acid concentration, this approach serves to illustrate the typical range of concentrations.
Figure 6 confirms the lack of new particle observations in the sectors $\mathrm{C}$ and $\mathrm{D}$ and highlights the clear relationship between $A_{A}$ and new particles. The Spearman rank correlation coefficient of the overall data set is 0.50 , that for the data in sectors $\mathrm{A}$ and $\mathrm{D}$ is 0.58 and 0.18 , respectively, and there is insufficient data for analysis in sector $C$. Very few particles are observed at $A_{A}$ less than $10^{6}$ (approximately $10^{5}$ molecules $\mathrm{cm}^{-3}$ of sulphuric acid), and most new particle observations occur at $A_{A}$ values of $10^{7}$ or greater (approximately $10^{6}$ molecules $\mathrm{cm}^{-3}$ sulphuric acid). The linear fit (solid line) showing the maximum number of $N_{5}$ observed at any $A_{A}$ compares very favorably with a similar analysis by Weber et al., [1997], performed on data taken at a remote continental site. They used measured sulphuric acid concentrations to show that the maximum ultrafine particle ( 3 to 4 $\mathrm{nm})$ concentrations increased from 10 at $10^{5}$ to 500 at $3 \times 10^{6}$ 
Table 1. Average Daytime Values (Taken Between 0600 and 1800) of Acid Availability $A_{A}$ and $5 \mathrm{~nm}$ Particle Concentration $N_{5}$ for 7 Different Days.

\begin{tabular}{lccc}
\hline Day & Sector & $\begin{array}{c}\text { Daytime Average } A_{A} \\
\text { (Arbitrary Units) }\end{array}$ & $\begin{array}{c}\text { Daytime Average } \\
N_{5} \text { (Particles } \mathrm{cm}^{-3} \text { ) }\end{array}$ \\
\hline June 21 & $\mathrm{C}$ & $0.8 \times 10^{7}$ & 3.4 \\
June 23 & $\mathrm{D}$ & $0.6 \times 10^{7}$ & 6.6 \\
June 24 & $\mathrm{D}$ & $0.4 \times 10^{7}$ & 6.9 \\
June 25 & $\mathrm{A}$ & $1.5 \times 10^{7}$ & 28.0 \\
June 26 & $\mathrm{D}$ & $0.2 \times 10^{7}$ & 4.6 \\
June 28 & $\mathrm{A}$ & $1.0 \times 10^{7}$ & 60.8 \\
June 29 & $\mathrm{A}$ & $1.6 \times 10^{7}$ & 52.2 \\
\hline
\end{tabular}

The 3 days identıfied as sector $A$ contrast markedly with the 4 when new particles were not observed. The values of acid availability are approximately an order of magnitude higher than the $\mathrm{H}_{2} \mathrm{SO}_{4}$ concentration (see text).

molecules $\mathrm{cm}^{-3}$. The measurements by Weber et al. [1997] are of descending air at a site high in the Rocky Mountains, very different conditions to those experienced at Weybourne.

In sector $\mathrm{A}$ there are a considerable number of observations of $A_{A}$ up to $10^{8}$, mostly associated with new particles. However, in sector D there are very few observations of $A_{A}$ greater than $10^{6}$. Clearly, the increase in availability of $\mathrm{H}_{2} \mathrm{SO}_{4}$ in sector A over that in sector $D$ is closely linked to the formation of new particles. However, significant numbers of new particles were measured at values of $A_{A}$ as low as $10^{5}$ in sector $\mathrm{A}$, and this is not observed in sector $\mathrm{D}$, so other factors are affecting behavior in the different sectors. One possible effect may be the increased temperature in sector $D$.

To further illustrate the link between sulphuric acid availability and new particle formation, both $A_{A}$ and $N_{S}$ values were averaged between 0600 and 1800 for several days when all data were available. These daytime average values are compared in Table 1. Again, the differences between particle formation days and those when ultrafine particles are not observed are clear. On sector $A$ days the daytime average of $N_{5}$ was between 28 and 61 particles $\mathrm{cm}^{-3}$, and the $A_{A}$ varied between 1 and $1.6 \times 10^{7}\left(\sim 1-1.6 \times 10^{6}\right.$ molecules $\left.\mathrm{cm}^{-3}\right)$. On the other days the daytime average of $N_{5}$ did not exceed 7 particles $\mathrm{cm}^{-3}$, and the $A_{A}$ varied between 0.2 and $0.8 \times 10^{7}$ (approximately 2 and $8 \times 10^{5}$ molecules $\mathrm{cm}^{-3}$ ).

These results strongly implicate sulphuric acid in the formation of ultrafine particles in rural areas, but $\mathrm{H}_{2} \mathrm{SO}_{4}-\mathrm{H}_{2} \mathrm{O}$ binary nucleation rates are several orders of magnitude too slow to form the number of particles observed. Ammonia mixing ratios have previously been made at Weybourne, and mixing ratios were always greater than $200 \mathrm{pptv}$, over 2 orders of magnitude larger than the calculated $\mathrm{H}_{2} \mathrm{SO}_{4}$ concentrations in this study and those measured by others at different locations [Eisele and Tanner, 1993; Weber et al., 1997]. $\mathrm{NH}_{3}$ is likely to always be in excess in these environments, and ternary nucleation processes involving $\mathrm{H}_{2} \mathrm{SO}_{4}-\mathrm{H}_{2} \mathrm{O}-\mathrm{NH}_{3}$ can generate a much larger number of particles because the initial clusters are predicted to be more easily energetically stabilized than in the binary case [Coffman and Hegg, 1995].

\subsection{Growth of Nucleated Particles}

Once these small particles are formed, they need to grow from diameters of around $1 \mathrm{~nm}$ to above $3 \mathrm{~nm}$ before they are detected, and clearly there will be a time delay between their initial formation and observation. Figure 5 provides evidence for this, in the morning precursor concentration increased with solar UV flux; however, $5 \mathrm{~nm}$ particles were not observed for about an hour. This delay time is different on individual days and varied from 30 to $90 \mathrm{~min}$. If the formation of stable particles from the gas phase takes place rapidly as Coffman and Hegg [1995] suggest, then this delay is largely due to the growth time from initial nucleation to an observable size. The two processes influencing growth to observable sizes are coagulation and condensation. Small particles of diameters less than $5 \mathrm{~nm}$ can coagulate with larger particles, intermode coagulation, or with each other, intramodal coagulation. The former process acts simply to decrease the number of particles in the ultrafine and subobservable mode and adds to the mass of the larger aerosol; it cannot be responsible for the growth of the mode itself. Intra-mode coagulation may increase the average size of particles within the ultrafine mode, though reducing the number. Kerminen and Wexler [1995] provide an approximation of the timescale for intramodal coagulation to increase the diameter of particles by a factor of $e, \tau-3 / K N$, where $N$ is the total number of particles in the mode. The coefficient for Brownian coagulation, $K$, is $10^{-9} \mathrm{~cm}^{3} \mathrm{~s}^{-1}$ throughout the particle size spectrum.

For intramodal coagulation to be an important process in growing particles to observable sizes at Weyboume the process must take place on timescales of about 1 hour, indicating that at least $10^{6}$ particles $\mathrm{cm}^{-3}$ are required to be present initially. It is difficult to assess the number of recently formed particles of below detectable size. However, we can estimate the timescale for growth by intramode coagulation of the most recently formed particles. Taking the large concentrations of 3 to $7 \mathrm{~nm}$ particles observed on the morning of June 17 (see Figure 3) as an upper limit, a total particle count of $10^{4} \mathrm{~cm}^{-3}$ was observed at Weybourne. Clearly, growth by coagulation is not effective at these sizes. In the absence of condensation the minimum number of freshly formed, assumed $1 \mathrm{~nm}$ diameter, particles needed to provide the volume of material held in particles between 3 and $7 \mathrm{~nm}$ can be estimated by assuming that intramodal coagulation was the only process occurring. For the case of June 17 this gives a maximum of $7 \times 10^{5}$ particles $\mathrm{cm}^{-3}$, barely sufficient for coagulation to occur within the observed timescales. It may be greater number densities of freshly nucleated, subdetectable particles were present initially. For instance, a concentration of $10^{7} \mathrm{~cm}^{-3}$ would lead to a corresponding timescale of $6 \mathrm{~min}$. However, scavenging by the existing particle population competes with this intramodal growth and acts to rapidly reduce ultrafine particle number. It is likely therefore that coagulation is important initially but reduces in importance and is a very slow process by the time the ultrafine particles reach observable sizes. Furthermore, a fraction of the observed mass will have been condensed from the gas phase onto prenucleated particles, again reducing the initial particle number concentration.

Likewise, we can assess the timescales for condensational growth. The early stages of growth by condensation are very slow because the Kelvin effect is very large for small particles, suppressing the supersaturation of the condensing species. As the particles grow, this reduces, and the condensation rate increases. Figure 7 shows the condensational growth rates for a binary system of sulphuric acid and water for different gas phase concentrations of the acid species assuming an accommodation coefficient of unity. The single parti- 


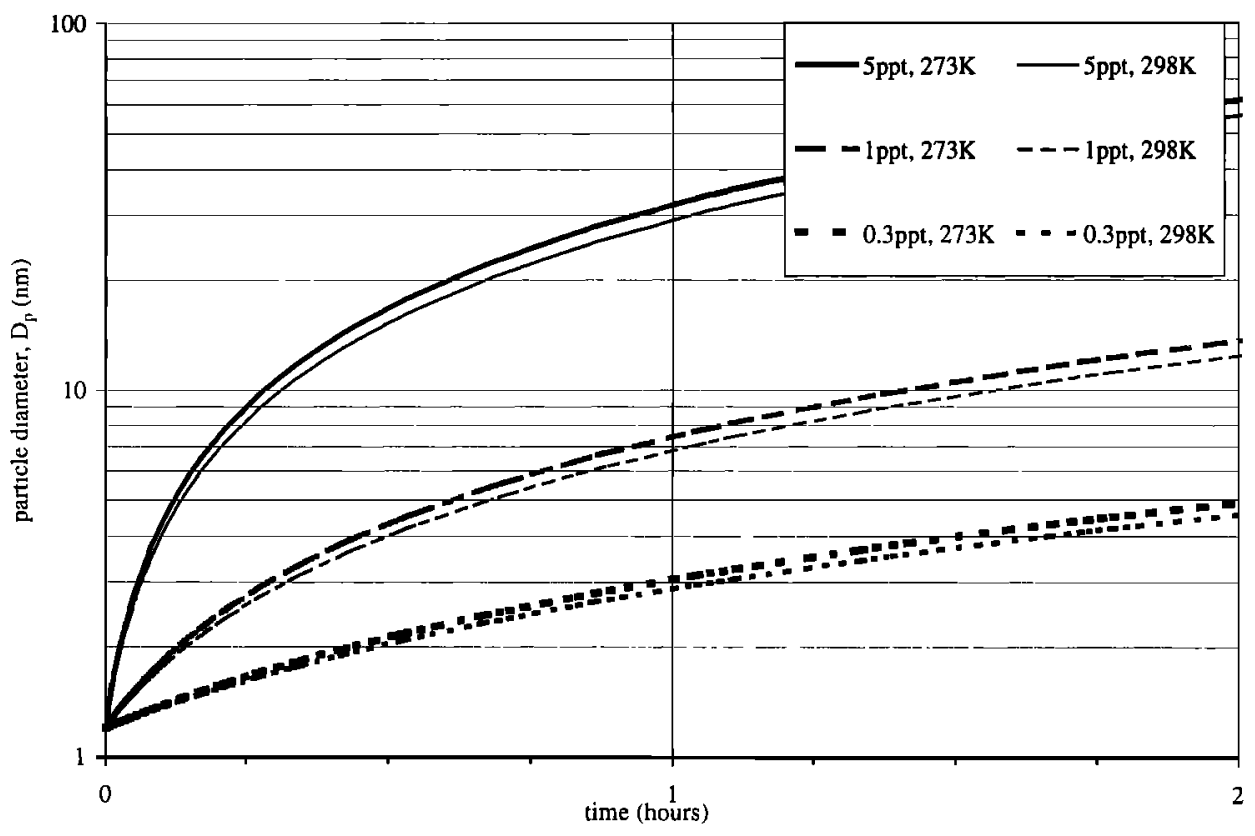

Figure 7. Modeled particle condensational growth rates for a binary system of sulphuric acid and water for different gas phase concentrations of the acid species assuming an accommodation coefficient of unity. The model considers both Kelvin and solute effects and assumes an initial composition of $25 \%$ by mass $\mathrm{H}_{2} \mathrm{SO}_{4}$; the effect of temperature is also shown. The particle is considered to grow from $1 \mathrm{~nm}$, and its evolution is shown as a function of time. The horizontal line indicates the size at which rapid particle concentration measurements were made (5 nm diameter).

cle condensation model is based on the approach of Kerminen et al. [1997] and determines the condensational flux of a vapor species using the transition regime expression of Fuchs and Sutugin [1970]. The model considers both Kelvin and solute effects and equilibrates with the ambient acid vapor saturation ratio and relative humidity to determine the composition of a particle of a given initial radius according to its Kelvin term [Kerminen and Wexler, 1997]. Whereas the model of Kerminen et al. [1997] considered multicomponent condensation using the thermodynamic model of Potukuchi and Wexler [1995a, b], only the condensation of $\mathrm{H}_{2} \mathrm{SO}_{4}$ and $\mathrm{H}_{2} \mathrm{O}$ were considered in this study, using the thermodynamic data of Ayers et al. [1980] and Taleb et al. [1996] and the surface tension data from Sabinina and Terpugow [1935]. Although different thermodynamic data have been used in this work, the differences between the model used here and that of Kerminen et al. [1997] are negligible compared to the input uncertainties. The particle is considered to grow from a stable cluster of $1.2 \mathrm{~nm}$ diameter, below detectable size, and its evolution is shown as a function of time. Although this model only considers a $\mathrm{H}_{2} \mathrm{SO}_{4}-\mathrm{H}_{2} \mathrm{O}$ system, the timescales for growth will be similar for any gas with an uptake coefficient of unity. Although the gradient of the curves appears steepest initially, the number flux of molecules to the surface of the particle is much less in the initial stages of growth.

The time taken to grow a freshly nucleated particle to the size at which it is measured by the DMA is dictated by the concentration of sulphuric acid in the gas phase. The model predictions show that this can vary from between 2 hours for an ambient $\left[\mathrm{H}_{2} \mathrm{SO}_{4}\right]=0.3 \mathrm{pptv}$ to around $40 \mathrm{~min}$ for $\left[\mathrm{H}_{2} \mathrm{SO}_{4}\right]=1$ pptv. The sulphuric acid concentrations during this experiment were in the range $10^{5}$ to $10^{8}$ molecules $\mathrm{cm}^{-3}$ during periods when enhanced $5 \mathrm{~nm}$ particle number concen- trations were observed. On June 28 (Figure 5) the sulphuric acid concentrations varied between 1 and $8 \times 10^{7}$ molecules $\mathrm{cm}^{-3}$ ( 0.4 and $\left.3 \mathrm{pptv}\right)$ during the period of enhanced particle concentrations (assuming the conversion from $A_{A}$ discussed previously). These observed levels of sulphuric acid and the calculated growth times are sufficient to account for the observed delay times between the onset of precursor production and observations of increased levels of $5 \mathrm{~nm}$ particles. Furthermore, the $20 \mathrm{~nm}$ particles, not shown in Figure 5, do not increase until around 1000 in the morning of June 28, 2 hours later than the increase in the $5 \mathrm{~nm}$ size. This time is again consistent with around 1 pptv of sulphuric acid present in the gas phase and shows that sulphuric acid availability controls the formation and growth of the ultrafine aerosol into the Aitken mode.

\section{Summary}

Continuous measurements of particle number distributions between 3 and $3000 \mathrm{~nm}$ diameter were made for a period of 16 days in June 1998 at a site on the east coast of the United Kingdom. Additional measurements with a DMA fixed to select $5 \mathrm{~nm}$ particles and a counter sampled at $1 \mathrm{~Hz}$ allowed investigation of the rapid variability of new particles and comparison with concurrent turbulence and precursor measurements.

During periods of northerly winds, no evidence of ultrafine aerosol $(<10 \mathrm{~nm})$ was observed in marine air at Weybourne. In contrast, ultrafine particles were observed regularly in rural air. Their presence was inhibited at higher temperatures, reduced concentrations of $\mathrm{SO}_{2}$, and large preexisting aerosol populations. New particles were not observed in air advected from continental Europe. These periods were marked by high 
temperatures $\left(>20^{\circ} \mathrm{C}\right.$ ) and very high aerosol surface areas $\left(2 \times 10^{5} \mathrm{~cm}^{2} \mathrm{~cm}^{-3}\right)$, which were caused by long-range transport of aged anthropogenic aerosol and also Saharan dust. On the remaining days of the experiment the air arriving at Weybourne was cyclonic, rapidly advecting cold, unstable air across the United Kingdom from the Atlantic Ocean. On these days, new particle concentrations were only observed to be substantially elevated when the air was from a west or northwesterly direction and not when it was from the southwesterly sector. The $\mathrm{SO}_{2}$ mixing ratios observed in the former sector were generally above $1 \mathrm{ppbv}$ and showed structure typical of a plume from a source tens of kilometers distant. Those in the latter sector were generally less than $1 \mathrm{ppbv}$ and often at the detection limit of the instrument. Large point sources of $\mathrm{SO}_{2}$ exist in an area approximately $100 \mathrm{~km}$ to the west and northwest of the site, and it is likely that these sources are responsible for the enhanced $\mathrm{SO}_{2}$ concentrations observed.

On days when new particles were formed, they grew rapidly from background levels between $30 \mathrm{~min}$ and 1.5 hours after the initial rise in UV radiation in the morning, implying a photolytic source of precursors. By early afternoon, new particle concentrations had again returned to background levels, and the particles formed during the morning had appeared to grow into the Aitken mode and add to its number concentration.

Although the general behavior of ultrafine particles was similar on each day they were observed, there were some significant differences. On several days a separate mode at $10 \mathrm{~nm}$ was observed at around the same time as the first measurements of $3 \mathrm{~nm}$ in the morning. On one of the days this mode was observed without any $3 \mathrm{~nm}$ particles present, but on a different day also occurred simultaneously with a large increase in $3 \mathrm{~nm}$ particles. These observations imply two separate processes are occurring, one of which is removed from the sampling location, the other of which is occurring more locally. Primary particle emissions from road traffic for instance cannot be responsible as there is no corresponding peak in the afternoon and the Aitken mode aerosol did not change significantly. There are insufficient data to draw any firm conclusions from these observations, and there are no clear systematic differences between these days in the meteorological parameters or trace gas concentrations. However, certainly clouds have been linked to new particle formation [Clarke et al., 1998] and could act as a more remote source for new particles during these measurements.

Fast measurements of $5 \mathrm{~nm}$ aerosol particles show no clear correlation between rapid temperature fluctuations and new particle concentrations on timescales of minutes, indicating that $5 \mathrm{~nm}$ particles are well mixed throughout the boundary layer. These data do not appear to show any evidence for enhancements of new particle formation by mixing predicted by Easter and Peters [1994] and Nilsson and Kulmala [1998], although the effects of small-scale turbulence could not be investigated using this approach. However, as the growth times of freshly nucleated particles to $5 \mathrm{~nm}$ diameter are of the same order as mixing timescales throughout the boundary layer, it is also possible that vertical variations in the nucleation rate will be obscured by mixing if larger particles are investigated.

The fast measurements of $5 \mathrm{~nm}$ particles are closely related to the availability of sulphuric acid vapor, implicating $\mathrm{H}_{2} \mathrm{SO}_{4}$ in the formation and initial growth of these new particles. The correlation between $\mathrm{H}_{2} \mathrm{SO}_{4}$ and $5 \mathrm{~nm}$ particles is very similar to that obtained previously in descending air at a remote location in the United States [Weber et al., 1997], a very different environment to the rural environment at Weybourne. Daily averaged values of $N_{5}$ and the availability of sulphuric acid show that an increase in new particle concentrations by approximately an order of magnitude occurs on days when there is a greater than threefold increase in the amount of acid available. The mechanism of particle formation remains unclear, but a likely candidate is a ternary process involving $\mathrm{NH}_{3}$, in addition to $\mathrm{H}_{2} \mathrm{SO}_{4}$ and water [Coffman and Hegg, 1995]. In most locations, and certainly at the Weybourne site, ammonia is likely to be always in great excess, and so growth is largely determined by the availability of sulphuric acid.

The observations show a delay of between $30 \mathrm{~min}$ and 1.5 hours from the initial increase in the availability of $\mathrm{H}_{2} \mathrm{SO}_{4}$ vapor and the presence of $5 \mathrm{~nm}$ particles. If, as predicted by Coffman and Hegg [1995], ternary nucleation is rapid, then the observed delay is due to the growth of stabilized particles below observable size to $5 \mathrm{~nm}$ diameter. We have considered the timescales for this growth due to both coagulation and condensation. The former process will be significant if the particle concentration is greater than $10^{6} \mathrm{~cm}^{-3}$; these levels are never observed for particles greater than $3 \mathrm{~nm}$. However, sufficient mass exists in the observed ultrafine aerosol for initial number concentrations of $1 \mathrm{~nm}$ diameter particles to have been at least $10^{6}$ particles $\mathrm{cm}^{-3}$ in the absence of condensation. Condensation of $\mathrm{H}_{2} \mathrm{SO}_{4}$ onto particles of $1 \mathrm{~nm}$ diameter is restricted by the Kelvin effect, and initial growth will be slow, although the calculated growth times are of similar order to the observed delay times. In the model calculation, around 1 pptv $\mathrm{H}_{2} \mathrm{SO}_{4}$ is required to grow a particle from a nucleated cluster of $1 \mathrm{~nm}$ diameter to a measurable $5 \mathrm{~nm}$ particle in around $40 \mathrm{~min}$, in good agreement with the observations. It seems likely that as the timescales associated with both coagulation and condensation are approximately the same, they will both play a part in growing the nucleated particles. Coagulation will be important initially when the number concentrations of the small particles are high and condensation is limited by the Kelvin effect. After a short time in the growth of these particles, the number of particles will have decreased, reducing the effectiveness of coagulation, the Kelvin effect will lessen, and condensation will dominate as the particles reach observable sizes. Clearly, when less acid vapor is available, the particles may nucleate but may not be able to grow to measurable sizes. Even when new particles grow to observable sizes, low acid precursor concentrations lead to slow condensational growth; this can be seen on June 22 (Figure 3) when no obvious growth is observed. Subsequent growth of particles to the Aitken mode requires a period of sustained acid availability that is longer than the time required to grow the nucleated particles to sizes where other, more volatile vapors, such as $\mathrm{HNO}_{3}, \mathrm{HCl}$, and organic material, will also begin to condense [Kerminen et al. 1997].

Acknowledgements. Thanks to Phil Judge, Andrew Lovett, and Gilla Sunnenberg for the production of Figure 1 and to the British Atmospheric Data Centre for calculation of trajectories and access to ECMWF data. Thanks also to Peter Kelly for technical assistance before and during the experiment. We are grateful to the reviewers for their 
constructive comments. This work was supported by U.K. NERC grants GR9/03438 and GR3/R9686.

\section{References}

Allen, A.G., J. L. Grennfell, R. M. Harrison, J. James, and M. J. Evans, Nanoparticle formation in marine air masses: Contrasting behavior of the open ocean and coastal environments, Atmos. Res., 51, 1-14, 1999.

Ayers, G. P., R W. Gillett, and J L. Gras, On the vapor pressure of sulfuric acid, Geophys. Res. Lett., 7, 433-436, 1980.

Berresheim, H., F. L. Ejsele, D. J. Tanner, L. M. McInnes, D. C. Ramseybell and D. S. Covert, Atmospheric sulfur chemistry and cloud condensation nuclei (CCN) concentrations over the northeastern Pacific coast, J. Geophys. Res., 98, 12,701-12,711, 1993.

Birmilli, W., F. Stratmann, A. Wiedensohler, D. Covert, L. M. Russell, and $\mathrm{O}$ Berg, Determination of differential mobility analyzer transfer functions using identical instruments in series. Aerosol. Sci. Technol., 27, (2), 215-223, 1997.

Clarke, A. D., Atmospheric nuclel in the remote free troposphere, $J$. Atmos. Chem., 14, 479-488, 1992.

Clarke, A. D., J. L. Varner, F. Eisele, R. L. Mauldin, D Tanner, and M. Litchy, Particle production in the remote marine atmosphere: Cloud outflow and subsidence during ACE 1,J. Geophys. Res., $103,16,397-16,409,1998$.

Coffman, D. J., and D. A. Hegg, A preliminary study of the effect of ammonia on particle nucleation in the marine boundary layer, $J$. Geophys. Res., 100, 7147-7160, 1995.

Covert, D. S., V. N. Kapustin, P. K. Quinn, and T. S. Bates, New particle formation in the marine boundary layer, J. Geophys. Res. 97, 20,581-20,589, 1992

Covert, D. S., V. N. Kapustın, T. S. Bates, and P K. Quinn, Physical properties of marine boundary layer aerosol particles of the midPacific in relation to sources and meteorological transport, $J$. Geophys. Res., 101, 6919-6930, 1996.

Easter, R C., and L. K. Peters, Binary nucleation: Temperature and relative humidity fluctuations, nonlınearity, and aspects of new particle production in the atmosphere, J. Appl Meteorol., 33, 775-784, 1994.

Eisele, F. L., and D. J. Tanner, Measurement of the gas phase concentration of $\mathrm{H}_{2} \mathrm{SO}_{4}$ and methane sulfonic acid and estimates of $\mathrm{H}_{2} \mathrm{SO}_{4}$ production and loss in the atmosphere, $J$ Geophys. Res., 98, 9001-9010. 1993

Forbcrich, O., T. Pfeıffeı, M. Spiekermann, J Walter, F. J. Comes, R. Grigonis, K. C. Clemitshaw, and R. A. Burgess, Measurement of the diurnal variation of the $\mathrm{OH}$ radical concentration and analysis of the data by modeling, J. Atmos. Chem., 33, 155-181, 1999.

Fuchs, N. A., and A. G. Sutugin, Highly Dispersed Aerosols, Butterwoth-Heinemann, Woburn, Mass., 1970

Grennfell, J. L, et al., An analysis of rapid increases in condensation nucle1 concentrations at a remote site in western Ireland, J. Geophys Res., 104, 13,771-13,780, 1999.

Hamerı, K., M. Kulmala, P. Aalto, K. Leszczynskı, R. Visurı, and K Hamekoski, The investigations of aerosol particle formation in urban background area of Helsinki, Atmos. Res., 41, 281-298, 1996.

Jefferson, A., F. L. Eisele, P. J. Ziemann, R. J. Weber, J. J. Mart1, and $\mathrm{P}$. $\mathrm{H}$. McMurry, Measurements of the $\mathrm{H}_{2} \mathrm{SO}_{4}$ mass accommodation coefficient onto polydisperse aerosol, J. Geophys. Res., $102,19,021-19,028,1997$.

Kerminen, V. M., and A. S. Wexler, Growth laws for atmospheric aerosol particles: An examination of the bimodality of the accumulation mode, Atmos. Environ., 29, 3263-3275, 1995.

Kerminen, V. M , A. S. Wexler, and S. Potukuchi, Growth of freshly nucleated particles in the troposphere: Roles of $\mathrm{NH}_{3}, \mathrm{H}_{2} \mathrm{SO}_{4}$, $\mathrm{HNO}_{3}$, and $\mathrm{HCl}$, I. Geophys. Res , I02, 3715-3724, 1997.

Kulmala, M., A. Laaksonen, and L. Pirjola, Parameterizations for sulphuric acid/water nucleation rates, J. Geophys. Res., J03, 8301-8307, 1998.

Mäkelä, J. M., P. Aalto, V. Jokinen, T. Pohja, A. Nissinen, S. Palmroth, T. Markkanen, K. Seitsonen, H. Lihavainen, and M. Kulmala, Observations of ultrafine aerosol particle formation and growth in boreal forest, Geophys. Res. Lett., 24, 1219-1222, 1997.

Nilsson, E. D., and M. Kulmala, Potential for atmospheric mixing processes to enhance the binary nucleation rate, J. Geophys. Res., 103, 1381-1389, 1998.

O'Dowd, C., et al., On the photochemical production of new particles in the coastal boundary layer, Geophys. Res. Lett., 26, $1707-$ $1710,1999$.

Penkett, S. A., J. M. C. Plane, F. J. Comes, K. C. Clemitshaw, and H. Coe, The Weybourne Atmospheric Observatory, J. Atmos. Chem., 33, 107-110, 1999.

Pirjola, L., and M. Kulmala, Modeling the formation of $\mathrm{H}_{2} \mathrm{SO}_{4}-\mathrm{H}_{2} \mathrm{O}$ partıcles in rural, urban and marine conditions, Atmos. Res., 46 , $321-347,1998$

Pitzer, K. S., Theory: Ion interaction approach, in Activity Coefficients in Electrolyte Solutions, vol.1, edited by R M. Pytkowicz, pp. 209-265, CRC Press, Boca Raton, Fla., 1979.

Potukuchı, S., and A. S. Wexler, Identifying solid-aqueous-phase transitions in atmospheric aerosols, 1, Neutral-acidity solutions Atmos. Environ., 29, 1663-1676, 1995a.

Potukuchi, S., and A. S. Wexler, Identifying solid-aqueous-phase transitions in atmospheric aerosols, 2, Acidic solutions, Atmos. Environ., 29, 3357-3364, 1995 b.

Radke, L. F., and P V Hobbs, Humidity and particle fields around some small cumulus clouds, J. Atmos. Sci., 48, 1190-1193, 1991.

Sabinına, L., and L. Terpugow, Die Oberflächenspannung des systems schwefelsäure - Wasser, Z. Phys. Chem., A, 173, 237-241, 1935.

Saros, M. T., R. J. Weber, J. J. Marti, and P.H. McMurry, Ultrafine aerosol measurements using a condensation nucleus counter with pulse height analysis, Aerosol Sci. Technol., 25, 200-213, 1996.

Schwartz, S. E., Mass-transport considerations pertinent to aqueous phase reactions of gases in liquid-water clouds, in Chemistry of Multiphase Atmospheric Systems, edited by W. Jaeschke, NATO ASI Ser., Ser G, 6, 415-471, 1986.

Stull, R. B., An Introduction to Boundary Layer Meteorology, Kluwer Acad. Norwell, Mass., 1988.

Taleb, D. E., J. L. Ponche, and P. Mirabel, Vapor pressures in the ternary system water-nitric acid-sulfuric acid at low temperature: A reexamination, J. Geophys. Res., 101, 25,967-25,977, 1996.

Weather Log, Weather Log for June 1998, Weather, 53, (8), 1998.

Weber, R. J, P. H. McMurry, F. L. Eisele, and D. J. Tanner, Measurement of expected nucleation precursor species and 3 to $500 \mathrm{~nm}$ diameter particles at Mauna Loa Observatory, Hawai, J. Atmos. Sci, 52, 2242-2257, 1995.

Weber, R J., J. J. Martı, P. H. McMurry, F. L. Eisele, D. J Tanner, and $A$. Jefferson., Measurements of new particle formation and uluafine particle growth rates at a clean continental site, J. Geophys. Res., I02, 4375-4385, 1997.

Weber, R J., P. H. McMurry, L. Mauldın, D. Tanner, F. Eısele, F. Brechtel, S Kredenweis, G. Kok, R. Schillawski and D. Baumgardner, A study of new particle formation and growth involving biogenic trace gas species measured during ACE 1,J. Geophys. Res., I03,16,385-16,396, 1998.

Weber, R J., P. H. McMurry, R. L. Mauldin III, D. J. Tanner, F. L. Essele, A. D. Clarke, and V. N. Kapustin, New particle formation in the remote troposphere: A comparison of observations at various sites, Geophys. Res. Lett., 26, 307-310, 1999.

Williams, P. I., Construction and validation of a DMPS system for aerosol characterization, Ph.D. thesis, University of Manchester Institute of Scrence and Technology, Manchester, England, 1999.

Williams, P. I., T. W. Choularton, M. W. Gallagher, H. Coe, and K. N. Bower, Results of monttoring ultrafine, fine and accumulation mode particles above an urban canyon within the city of Manchester, J. Aerosol Sci., 29, suppl. 1, 593-594, 1998.

Winkelmayr, W., G. P. Reischl, A. O. Lindner, and A. Berner, A new electromobility spectrometer for the measurement of aerosol size distributions in the size range from 1 to $1000 \mathrm{~nm}, J$. Aerosol Sci. 22, 289-296, 1991 .

K. M. Beswick, K. N. Bower, T. W. Choularton, H. Coe, M. W. Gallagher, and P. I. Williams, Physics Department, UMIST, P.O. Box 88, Manchester M60 1QD, England, U.K. (hugh.coe@umist.ac. uk)

G. McFiggans, School of Environmental Sciences, University of East Anglia, Norwich NR4 7TJ, England, U.K.

(Received October 29, 1999, revised April 3, 2000; accepted April 10, 2000.) 